\title{
Development of a novel high performance cake-less filtration system
}

\author{
T. Mori, H. Satone, T. Hirata \& J. Tsubaki \\ Department of Molecular Design and Engineering, \\ Graduate School of Engineering, Nagoya University, Japan
}

\begin{abstract}
A new cake-less continuous filtration system with a spiral guide rod inserted into a ceramic tube filter and slurry prepared in a well dispersion state has been developed. We tried to filter some difficult to filter materials such as iron oxide and activated sludge. Especially, the algal suspension and activated sludge was not able to be filtrated by a conventional filtration system like filter press. Concentrated slurries of iron oxide and activated sludge were discharged at $35 \mathrm{vol} \%$ and 7.55 mass $\%$ respectively. The concentrates of every sample retained flowability. In addition, to apply this system to a real process, we tried to calculate the filter tube number from the relationship between the filtration flux and slurry concentration. As a result, the size of this system can be expected to be very compact. Also, in this system, the batch operation was more effective than continuous operation.
\end{abstract}

Keywords: dispersant, dynamic filtration, purification, solid-liquid separation, suspension, thickening, washing.

\section{Introduction}

In the cake filtration used to concentrate slurry in many industries, there are various problems such as; the packing fraction of the formed cake is low because of the added flocculants, the cake formed on the filter media has no flowability, and therefore has to be scraped mechanically, which makes the instrument becomes big and complicated.

In order to overcome these problems, we developed a novel filtration system, in which a dispersant is added instead of a flocculant and the concentrate can be collected continuously without any scraper because the concentrate still has 
fluidity [1]. However, in our previous system, it is difficult to scale up due to its structure [2]. Thus, in our previous report [3], the new cake-less filtration system using a ceramic tube filter within the spiral guide rod was developed. In this work, the purpose is to filtrate various hardly filterable materials using the new filtration system and to discuss the scale-up of the system. In this paper, we tried to concentrate various hardly filterable materials such as sericite, iron oxide, algal suspension and activated sludge of the excrement of farm animals. In addition, we tried to calculate the number of the ceramic filter that were necessary to concentrate from the target concentration and throughput. Moreover, we also compared efficiency of the batch operation with that of continuous operation.

\section{Experiments}

\subsection{Filtration unit}

The filtration system used in this paper is same as in our previous paper. Slurry in the feed tank was fed into the filter part at a set pressure by pump. The filter media was a ceramic tube. The pore size was $1.5 \mu \mathrm{m}$ and the inner diameter, outer diameter and length were 9, 12, and $300 \mathrm{~mm}$, respectively. The spiral guide rod was set in the ceramic tube. Material of the core rod of the spiral guide rod was acrylic. On the core rod, a lead wire was wound as a spiral guide. The diameter of the core rod and the lead wire were 6 and $1.5 \mathrm{~mm}$, respectively. The pitch of the spiral guide rod was $10 \mathrm{~mm}$. In order to concentrate the slurry, only the dense slurry was returned to the tank. The filtration pressure and flow rate of circulation were controlled by the pressure regulator and the valve at outlet of the filter and measured by a pressure gauge and flow meter, respectively. The filtration flux was calculated by weighting the filtrate during a period of time.

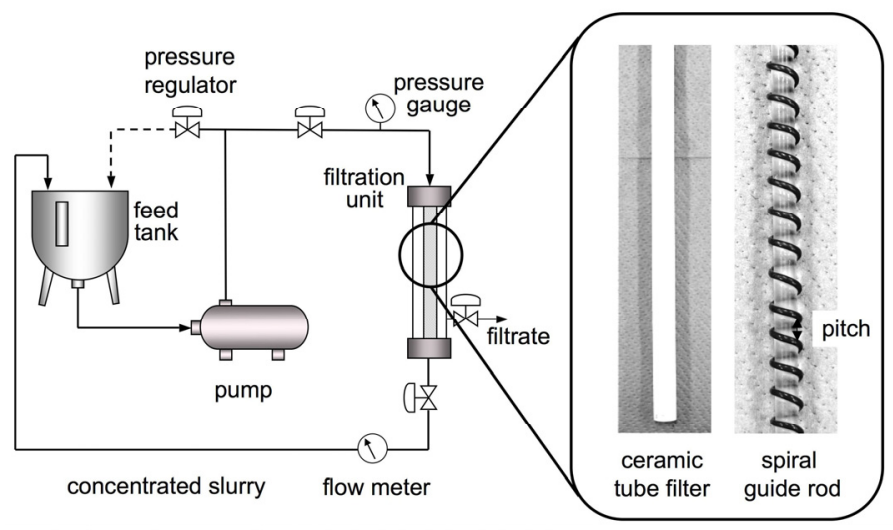

Figure 1: $\quad$ Schematic illustration of the new filtration system. 


\subsection{Concentration of iron oxide slurry}

The iron oxide slurry (density of $5.2 \mathrm{~g} \cdot \mathrm{cm}^{-3}$ ) was supplied by the JFE Chemical Co. Ltd. The initial concentration was $8.3 \mathrm{vol} \%$ (32 mass $\%$ ). Now, in the plant, this slurry was concentrated up to 70 mass $\%$ (31 vol\%) using a filter press.

This iron oxide slurry from ironworks originally contained ammonium sulfate as a flocculant. Therefore, we used the water glass as a dispersant. The additive amount of the dispersant was $2.4 \mathrm{mg}^{-1} \mathrm{~g}^{-1}$ iron oxide. The filtration pressure was $0.4 \mathrm{MPa}$ and the flow rate of the concentrate was $16.8 \mathrm{~L} \cdot \mathrm{min}^{-1}$.

\subsection{Concentrating of activated sludge of the excrement of farm animals}

The initial concentration of the activated sludge of the excrement of farm animals was 1.2 mass $\%$. The state of the slurry was a good dispersion state without the addition of any dispersant. The slurry was concentrated up to 7.5 mass $\%$ by sunlight because it was also not able to be filtrated by a conventional filtration system like a filter press. The filtration pressure was $0.38 \mathrm{MPa}$ and the flow rate of the concentrate was $17 \mathrm{~L} \cdot \mathrm{min}^{-1}$.

\section{Results and discussions}

\subsection{Concentration of iron oxide slurry}

Figure 2 shows the experimental results of the iron oxide slurry. The filtration flux also decreased gradually while the slurry was being concentrated. In this test, the slurry was concentrated up to $35 \mathrm{vol} \%$ (74 mass $\%$ ) which is comparable to a conventional filter press. The pump did not work well at $35 \mathrm{vol} \%$, although the flowability of the concentrate was good as shown in Figure 3. Therefore, it also seems to be possible to concentrate the slurry more highly using a high performance pump.

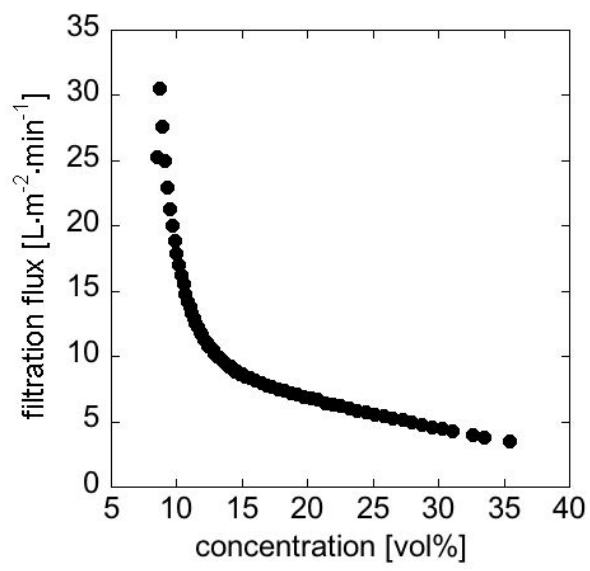

Figure 2: Relationship between the filtration flux and the volumetric concentration of the iron oxide slurry. 


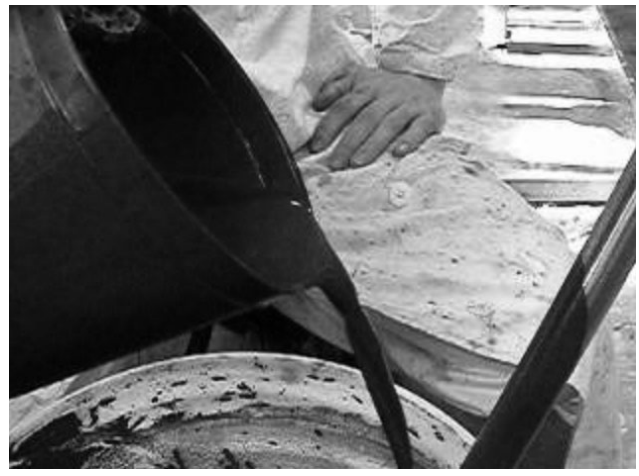

Figure 3: $\quad$ Flowability of the concentrated iron oxide slurry.

\subsection{Concentrating of activated sludge of the excrement of farm animals}

Figure 4 shows the relationship between the filtration flux and the slurry concentration. This slurry also could be filtrated without fouling and the filtration flux did not change although the filtration flux rapidly decreased because the particles fouled the filter just after starting filtration like the algal suspension. In this experiment the filtration test had to stop at 7.55 mass $\%$ because of shortage of the feed slurry. However, there was no cake observed on the spiral guide rod after end of concentration test and the dense slurry had flowability as shown in Figure 5. Therefore, it seems to be possible to concentrate more highly.

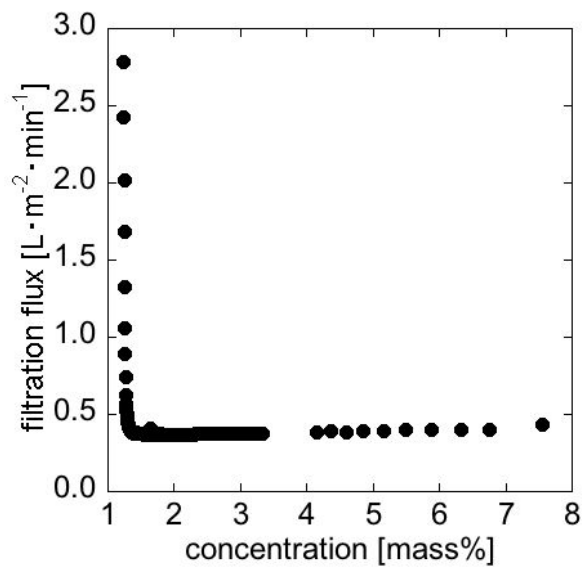

Figure 4: Relationship between the filtration concentrated flux and the slurry concentration of the activated sludge. 


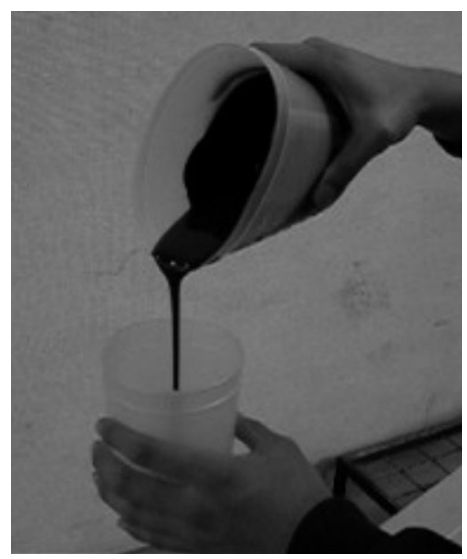

Figure 5: $\quad$ Flowability of the activated sludge.

\section{Scale-up of the system}

The scale-up of the instrument is necessary to treat a large quantity of samples. In this system, the scale-up is to increase the number of ceramic filters. The number of ceramic filters can be calculated from the required filtration area, and therefore, we tried to determine the required filtration area of each of the cases of batch operation and continuous operation from the target concentration and throughout, and compared the results of each.

\subsection{Batch operation}

If there is a correlation between the filtration flux and slurry concentration, the required filtration time and filtration area can be calculated as follows.

We considered that the initial $(t=0)$ slurry, of which the volume was V0 $\left[\mathrm{m}^{3}\right]$ and the concentration is $\phi_{0}[-]$, was concentrated to $V\left[\mathrm{~m}^{3}\right]$ and $\phi[-]$ during $t[\mathrm{~s}]$. Afterwards, during $\mathrm{d} t[\mathrm{~s}]$, the volume decreased as $A q(\phi) \mathrm{d} t\left[\mathrm{~m}^{3}\right]$. Here $A\left[\mathrm{~m}^{2}\right]$ and $q(\phi)\left[\mathrm{m}^{-1} \mathrm{~s}^{-1}\right]$ are the filtration area and the filtration flux respectively, and the concentration increase was $\mathrm{d} \phi[-]$. Assuming that there were no particles in the filtrate, this process can be described by the following equation from the material balance equation.

$$
V_{0} \phi_{0}=V \phi=(V-A q(\phi) \mathrm{d} t)(\phi+\mathrm{d} \phi)
$$

From this equation, the next equation can be derived.

$$
\mathrm{d} t=\frac{V_{0} \phi_{0}}{A \phi^{2} q(\phi)} \mathrm{d} \phi
$$

This equation is integrated in the condition; $\left(t: 0 \rightarrow t, \phi: \phi_{0} \rightarrow \phi\right)$.

$$
t \cdot A=V_{0} \phi_{0} \int_{\phi_{0}}^{\phi} \frac{\mathrm{d} \phi}{\phi^{2} q(\phi)}
$$


From this equation, the relationship between the required filtration time and filtration area can be calculated.

\subsection{Continuous operation}

In the case of continuous operation, it is necessary to keep the concentration in the tank target concentration $\phi_{t}[-]$. In stable operation, the slurry, which has a concentration of $\phi_{0}[-]$, is fed at the flow rate of $V_{\mathrm{f}}\left[\mathrm{m}^{3} \cdot \mathrm{s}^{-1}\right]$, and the dense slurry, which has a concentration of $\phi_{\mathrm{t}}[-]$ was discharged at a flow rate of $V_{\mathrm{t}}\left[\mathrm{m}^{3} \cdot \mathrm{s}^{-1}\right]$. Then, the filtrate was drained at a flow rate of $A q(\phi) \mathrm{d} t\left[\mathrm{~m}^{3} \cdot \mathrm{s}^{-1}\right]$. From the material balance equation, these two following equations can be obtained.

$$
\begin{gathered}
V_{\mathrm{f}} \phi_{0}=V_{\mathrm{t}} \phi_{\mathrm{t}} \\
\left(1-\phi_{0}\right) V_{\mathrm{f}}=A q\left(\phi_{\mathrm{t}}\right)+\left(1-\phi_{\mathrm{t}}\right) V_{\mathrm{t}}
\end{gathered}
$$

From these two equations, we can calculate the required filtration area for the flow rate of feed slurry.

$$
A=\frac{V_{\mathrm{f}}\left(\phi_{\mathrm{t}}-\phi_{0}\right)}{\phi_{\mathrm{t}} q\left(\phi_{\mathrm{t}}\right)}
$$

In the case where the slurry which has a whole volume of $V_{\mathrm{s}}\left[\mathrm{m}^{3}\right]$ is filtrated during $t$ [s], the volume of $\alpha \bullet V_{\mathrm{s}}\left[\mathrm{m}^{3}\right](0<\alpha<1)$ is filtrated by batch operation, and the remaining volume of $(1-\alpha) \bullet \mathrm{Vs}\left[\mathrm{m}^{3}\right]$ is filtrated by continuous operation afterwards. The relationship between the required filtration time and filtration area of this case is expressed by following equation.

$$
t \cdot A=\alpha \cdot V_{\mathrm{s}} \cdot \phi_{0} \int_{\phi_{0}}^{\phi_{\mathrm{t}}} \frac{\mathrm{d} \phi}{\phi^{2} q(\phi)}+(1-\alpha) \cdot V_{\mathrm{s}} \cdot \frac{\phi_{\mathrm{t}}-\phi_{0}}{\phi_{\mathrm{t}} q\left(\phi_{\mathrm{t}}\right)}
$$

\subsection{Determination of the filter tube number of the concentrating system}

We considered the concentration of the whole volume of $1 \mathrm{~m}^{3}$ of each hardly filterable slurry. We tried to calculate the relationship between the required filtration time and filtration area of batch operation and continuous operation from Eqs. (3) and (7), respectively. In the case of continuous operation, $\alpha$ is assumed to be 0.2. However, it is difficult to measure the volumetric concentration of the activated sludge of the excrement of farm animals, so the mass concentration was used instead. $c[-]$ and $q(c)\left[\mathrm{kg}^{\circ} \mathrm{m}^{-2} \cdot \mathrm{s}^{-1}\right]$ were used

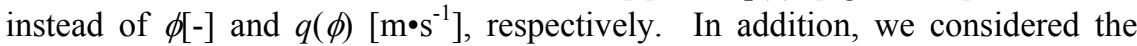
concentration of the total weight of $1000 \mathrm{~kg}$.

The correlation between the filtration time and the number of the filters are shown in Figures 6-7. In the case of the slurry that the filtration flux decreased gradually while the slurry was being concentrated, like in the iron oxide slurry, the batch operation was more effective than that of continuous operation. This is because, in case of continuous filtration, it is necessary to always keep the concentration in the tank at the target concentration, and therefore, the filtration 
flux is always late. However, in case of the batch filtration, we could use all filtration fluxes, including high filtration flux at a low concentration. On the other hand, in the case of the slurry where the filtration flux did not change although the filtration flux rapidly decreased just after starting filtration, like in the activated sludge of the excrement of farm animals, the efficiency of the continuous operation was not different from that of batch operation.

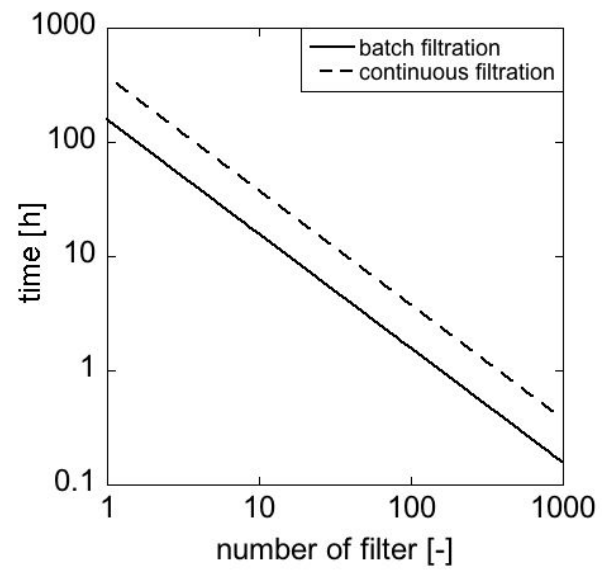

Figure 6: Correlation between the filtration time and the number of ceramic filters of the iron oxide slurry.

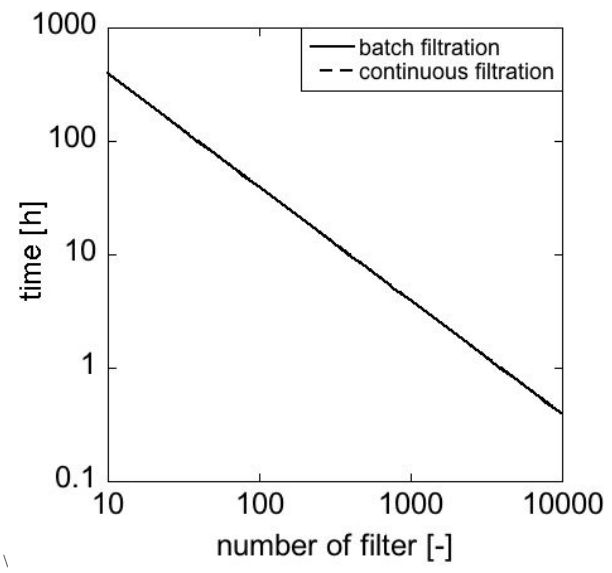

Figure 7: Correlation between the filtration time and the number of ceramic filters of the activated sludge.

The maximum number of filters that were necessary to concentrate to the target concentration during one hour by batch operation in the case of the activated sludge of the excrement of farm animals, was 3,950. 3,950 filters fit into the box in which the length, breadth and height are 1000, 1000 and $500 \mathrm{~mm}$, 
respectively. Compared with conventional filtration systems like a filter press, it is very compact, even when including the feed tank and pump.

\section{Conclusions}

In this paper, a kind of cross flow tubular ceramic filter with an inserted spiral guide rod was discussed. We tried to filter some hardly filterable materials such as iron oxide and activated sludge of the excrement of farm animals by the new system. Every sample was able to be concentrated up to enough concentration with flowability and no cake formed on the filter media. In addition, to apply this system to real processes, we were able to determine the filter tube number from the relationship between the filtration flux and slurry concentration. In every sample, the size of this system could be expected to be very compact. Also, in this system, the batch operation was more effective than continuous operation. From these results, this new system can be very useful in various industrial processes.

\section{References}

[1] Tsubaki, J, Mori, T., Unenbat, T., Ochirkhuyag, B., 2006. Development of a novel slurry condensation method by applying dispersant instead of flocculant, Journal of Society of Powder Technology Japan 43, 731-736.

[2] Ochirkhuyag, B., Mori, T., Tsubaki, J., Katsuoka, T., Satone, H., Choi, Sugimoto, T., 2008. Development of a High Performance Cake-less Continuous Filtration System, Chemical Engineering Science 63, 52745282.

[3] Katsuoka, T., Satone, H., Yamada, H., Mori, T., Tsubaki, J., 2010. Development of a novel high performance cake-less filtration system Optimization of operating conditions -, submitted to Chemical Engineering Science. 